\title{
Antimigraine medication use and associated health care costs in employed patients
}

\author{
Jun Wu • Mary D. Hughes $\cdot$ Matthew F. Hudson • \\ Peggy J. Wagner
}

Received: 10 October 2011/Accepted: 16 November 2011/Published online: 30 November 2011

(C) The Author(s) 2011. This article is published with open access at Springerlink.com

\begin{abstract}
Migraine is under diagnosed and suboptimally treated in the majority of patients, and also associated with decreased productivity in employees. The objective of this retrospective study is to assess the antimigraine medication use and associated resource utilization in employed patients. Patients with primary diagnosis of migraine or receiving antimigraine prescription drugs were identified from an employer-sponsored health insurance plan in 2010. Medical utilization and health care costs were determined for the year of 2010. Generalized linear regression was applied to evaluate the association between health care costs and the use of antimigraine medications by controlling covariates. Of 465 patients meeting the study criteria, nearly $30 \%$ that had migraine diagnosis were prescribed antimigraine medications, and $20 \%$ that had migraine diagnosis were not prescribed antimigraine medications. The remaining $50 \%$ were prescribed antimigraine medications but did not have migraine diagnosis. Patients with antimigraine medication
\end{abstract}

J. Wu ( $\bowtie)$

South Carolina College of Pharmacy, University of South

Carolina, Health Sciences Administration Bldg (MIPH),

701 Grove Road, Greenville, SC 29607, USA

e-mail: wujun@sccp.sc.edu

M. D. Hughes

Division of Neurology, Department of Medicine,

Greenville Hospital System, University Medical Group,

701 Grove Road, Greenville, SC, USA

M. F. Hudson · P. J. Wagner

Greenville Hospital System, University Medical Center,

701 Grove Road, Greenville, SC, USA

P. J. Wagner

Department of Family and Community Medicine,

University of South Carolina, 701 Grove Road, Health Sciences

Administration Bldg (MIPH), Greenville, SC, USA prescriptions showed lower frequency of emergency department visits than those without antimigraine medication prescriptions. Regression models indicated an increase in migraine-related health care costs by $86 \%$ but decreases in all-cause medical costs and total health care costs by 42 and $26 \%$, respectively, in the antimigraine medication use group after adjusting for covariates. Employed patients experienced inadequate pharmacotherapy for migraine treatment. After controlling for covariates, antimigraine prescription drug use was associated with lower total medical utilization and health care costs. Further studies should investigate patient self-reported care and needs to manage headache and develop effective intervention to improve patient quality of life and productivity.

Keywords Migraine - Antimigraine medication use · Health care costs $\cdot$ Employed patients

\section{Introduction}

Migraine is a chronic condition characterized by moderate to severe headaches. About 29.5 million Americans suffer from migraine, with an estimated $18 \%$ of women and $6 \%$ men directly affected [1-3]. The predominate (or primary) age to experience migraines is between 25 and 55, which coincides with an individual's most active employment period $[4,5]$. Consequently, migraine-attributable morbidity may adversely affect work productivity via absenteeism or presenteeism (compromised work productivity in the course of daily labor) [6]. Additionally, migraine sufferers may also experience compromised rest and leisure that indirectly affects labor productivity, and directly acerbates quality of life [7-9]. Studies suggest migrainerelated morbidity, particularly, accounts for costs incurred 
via decreased productivity, with United States' annual estimates between $\$ 13$ billion and $\$ 17$ billion [10-12]. Unfortunately, migraine is both under diagnosed and inadequately treated in the majority of patients. One study evaluated treatment patterns and health care use for chronic migraine in a general population, and demonstrated $87.6 \%$ of the patients with chronic migraine visited a health care provider to obtain appropriate care [13]. Nearly $32 \%$ of those patients received migraine-specific acute treatments and just 33\% were using preventive medications. Another study considered migraineurs' current patterns of health care use, and noted $48 \%$ of migraine suffers had seen a doctor for headache within the past year, $31 \%$ had never done so in their lifetimes, and $21 \%$ had not seen a doctor for headache for at least 1 year [1]. Of all the patients with migraine, $23 \%$ were treated with prescription drugs, and only $49 \%$ with over-the-counter medications only. Thus, previous studies suggest a care gap exists relative to evidence-based care strategies, and subsequent application in migraine management.

Although proper diagnosis is essential to optimal migraine management, increased burden may also be attributed to inadequate prescription drug therapy. Studies demonstrated improved medication use is associated with better clinical and economic outcomes in patients with chronic diseases. Specifically, unsustained statin use compromises benefits, such as reduced CHD risk, and creates substantial treatment costs attributed to otherwise preventable CHD events [14-17]. Balkrishnan's study also found a strong association between decreased antidiabetic medication use and increased health care service utilization in elderly with type 2 diabetes [18]. Currently, many studies on migraine and associated outcomes rely upon data gleaned via patient self-report surveys [1, 13, 19-21]. Knowledge of migraine-associated health outcomes in patients enrolled in employer-sponsored health insurance programs is very limited. Insights gleaned from a population having a common baseline of assured care access may help clarify where and how suboptimal patient outcomes persist. It is unclear whether there is a relationship between migraine medication use and total medical utilization and costs, especially in employed patients. Clarifying this relationship may elucidate the impact of explicit chronicity on total medical costs, and subsequently clarify comprehensive care coordination opportunities. Health care administrative data is a readily available source of employees' health care resource utilization, and may inform insights regarding clinical and economic outcomes. This study was designed to answer the following two primary questions: (1) What is the antimigraine prescription drug use pattern in patients enrolled in an employersponsored health plan? (2) How do the resource utilization and health care costs differ between patients receiving prescription drugs to treat migraine and those not receiving prescription drugs?

\section{Methods}

Data source and patient selection

De-identified claims data based on an employer-sponsored health plan were extracted by Advisory Board Company in Washington D.C. All patients with at least one primary diagnosis of migraine between January 1, 2010 and December 31, 2010 were identified by International Classification of Diseases, 9th revision (ICD-9) (346.xx). All patients receiving at least one prescription for a medication to treat migraine between January 1, 2010 and December 31,2010 were also identified by therapeutic category in the database (Table 1). Patients were required to be enrolled in the employer-sponsored health plan continuously during the year of 2010. Patients enrolled as dependents were excluded from the study. Given the bidirectional influence of migraine and major depression described in previous studies [22, 23], we considered comorbid depression if patients presented at least one primary diagnosis of major depression or received at least one prescription for an antidepressant or antianxiety medication shown in Table 1 during the study period. All eligible patients were divided into two groups: patients who received antimigraine medications and those who did not.

\section{Medical utilization}

Total medical utilization with any conditions within 1 year was evaluated by hospitalization frequency, emergency department (ED) visits, and total numbers of outpatient and physician office visits. Patients with at least one time hospitalization or ED visit during the study period were categorized as hospitalization or ED visit during the study period. Medical utilization related to migraine was identified by primary diagnosis codes (346.xx).

\section{Health care costs}

Health care costs were evaluated based on third party payer perspective. Reimbursement rates paid by the employer were used to compute annual total and migraine-related health care costs, including medical care and pharmacy costs. Medical care costs were defined as the sum of inpatient, ED, hospital outpatient, and physician office visit costs. Annual total health care costs were the sum of medical and pharmacy costs associated with any conditions during the 1-year study period. Migraine-related health care costs were identified by primary diagnosis code of 
Table 1 Medications for migraine and depression used by participants

\begin{tabular}{|c|c|}
\hline Antimigraine medications & Antidepressants \\
\hline $\begin{array}{l}\text { Acetaminophen/caffeine/ } \\
\text { isometheptene mucate }\end{array}$ & Alprazolam \\
\hline $\begin{array}{l}\text { Acetaminophen/dichloralphenazone/ } \\
\text { isometheptene mucate }\end{array}$ & $\begin{array}{l}\text { Alprazolam extended- } \\
\text { release }\end{array}$ \\
\hline Almotriptan malate & Amitriptyline hydrochloride \\
\hline Dihydroergotamine mesylate & $\begin{array}{l}\text { Amitriptyline- } \\
\text { chlordiazepoxide }\end{array}$ \\
\hline Eletriptan hydrobromide & Budeprion hydrochloride \\
\hline Ergotamine-caffeine & $\begin{array}{l}\text { Budeprion hydrochloride } \\
\text { extended-release }\end{array}$ \\
\hline Frovatriptan succinate & $\begin{array}{l}\text { Budeprion hydrochloride } \\
\text { sustained-release }\end{array}$ \\
\hline Naratriptan hydrochloride & Citalopram hydrobromide \\
\hline Rizatriptan benzoate & $\begin{array}{l}\text { Clomipramine } \\
\text { hydrochloride }\end{array}$ \\
\hline Sumatriptan succinate & Clorazepate dipotassium \\
\hline $\begin{array}{l}\text { Sumatriptan succinate/naproxen } \\
\text { sodium }\end{array}$ & Desipramine hydrochloride \\
\hline \multirow[t]{19}{*}{ Zolmitriptan } & Desvenlafaxine succinate \\
\hline & Diazepam \\
\hline & Doxepin hydrochloride \\
\hline & Duloxetine hydrochloride \\
\hline & Escitalopram oxalate \\
\hline & Fluoxetine hydrochloride \\
\hline & $\begin{array}{l}\text { Fluoxetine hydrochloride/ } \\
\text { olanzapine }\end{array}$ \\
\hline & Fluoxetine pamoate \\
\hline & Imipramine hydrochloride \\
\hline & Lorazepam \\
\hline & Mirtazapine \\
\hline & Nortriptyline hydrochloride \\
\hline & Oxazepam \\
\hline & Paroxetine hydrochloride \\
\hline & Paroxetine mesylate \\
\hline & Phenelzine sulfate \\
\hline & Trazodone hydrochloride \\
\hline & Venlafaxine hydrochloride \\
\hline & $\begin{array}{l}\text { Venlafaxine hydrochloride } \\
\text { extended-release }\end{array}$ \\
\hline
\end{tabular}

migraine (346.xx) for medical care costs and by prescription drugs to treat migraine for pharmacy costs. Total migraine-related health care costs were the sum of migraine-related medical and pharmacy costs during the 1 -year study period.

Risk index (RI) and Care gap index (CGI) [24]

$\mathrm{RI}$ is an index value created by using D2Hawkeye risk modeling system to indicate the risk a member will become a catastrophic case, and is based on the number of comorbidities presented. Similarly, CGI is an index value indicating the degree to which a member complies with recommended care guidelines associated with their age and existing conditions. Both of these scores provided by the health insurance program are routinely used by a number of care management program directors and managers to identify specific patient groups that may particularly benefit from tailored care management programs. These two variables were included in our regression models as covariates for adjustment.

\section{Data analysis}

Univariate analyses were used to compare patient characteristics, unadjusted medical utilization, and health care costs between the two groups, namely, those using antimigraine medications and those not using antimigraine medications. Chi-square tests were applied to analyze categorical variables and $t$ tests were used for continuous variables. Nonparametric tests (Wilcoxon rank-sum test) were used to compare various health care costs between two groups.

Generalized linear regressions with log link and gamma distribution were considered to analyze the associations between health care costs and the use of antimigraine medications after adjusting for diagnosis of migraine, age, gender, comorbid depression, CGI, and RI. The level of significance was preset at $\alpha=0.05$. All statistical analyses were conducted by SAS 9.2 (SAS Institute, Cary, NC).

\section{Results}

Figure 1 and Table 2 display the patient selection and characteristics of our study population enrolled in an employer-sponsored health plan during the study period (January 1, 2011 to December 31, 2011). A total of 465 patients (5.9\% of total employees enrolled in the employersponsored health insurance plan in 2010) met the study inclusion and exclusion criteria, with an average age of 43.5 years. Females accounted for nearly $95 \%$ of the study population; two-thirds of the patients had depression diagnosis or used antidepressants during the study period. Of the patients receiving antimigraine medications, $64 \%$ did not have migraine diagnosis. In contrast, $43 \%$ of patients diagnosed with migraines, did not take antimigraine medications.

Table 3 compared unadjusted medical utilization and health care costs between patients using and not using antimigraine medications. Patients receiving antimigraine medications evidenced 12.3 and $7.2 \%$ fewer all-cause and migraine-related ED visits, respectively, as compared to 
those not receiving antimigraine medications. Groups using antimigraine medication also evidenced fewer outpatient and office visits. Pharmacy cost for antimigraine medication use accounted for $78 \%$ of total migraine-related costs. An increase in all-cause pharmacy cost by $\$ 1,010$ and decrease in all-cause medical cost by $\$ 3,407$ were shown in the antimigraine medication use group.

Table 4 presents associations between various health care costs and the use of migraine medications after adjusting for diagnosis of migraine, age, gender, CGI, RI, and comorbid depression. After translating the log-transformed coefficients based on generalized linear regressions, we found even though patients receiving antimigraine medications showed increased migraine-related health care costs by $86 \%$, all-cause medical costs and total health care costs were reduced significantly by 42 and $26 \%$, respectively, when all the other covariates remained constant.

\section{Discussion}

The purpose of this study was to evaluate the use pattern of migraine prescription drugs and its effect on the health care costs in patients enrolled in an employer-based health care program. Our study results indicated that nearly $45 \%$ of the patients with diagnosis of migraine did not receive appropriate pharmacotherapy and that nearly $65 \%$ of the patients who received antimigraine medications did not have migraine diagnosis. This study also found that migraine medication costs were the major proportion of migrainerelated costs in patients, but total cost saving was shown in the patients due to significantly decreased medical costs.

Total number of employees enrolled in the health plan $2010(n=7878)$ Females $(n=6245)$, males $(n=1633)$

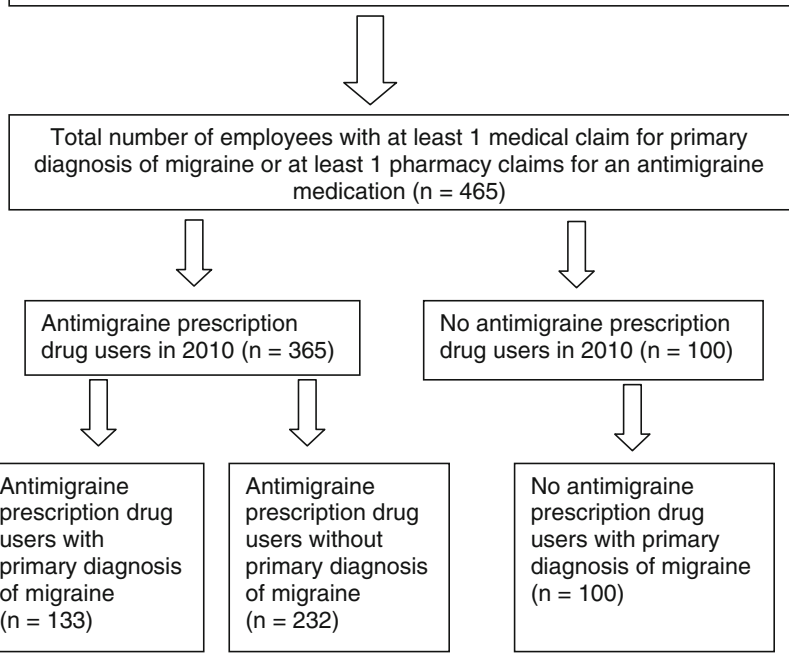

Fig. 1 Patient selection from an employer-sponsored health insurance plan in 2010
These findings may underscore the importance of improving current evidence-supported strategies (such as appropriate pharmacotherapy and prophylactic regimens) and incorporating adjunct interventions, such as patient self-management. These efforts may improve the quality of life and productivity in employed patients with migraine.

Pharmacotherapy, especially the triptan drug class, accounts for the most direct costs relative to migraine care; given the expense, it is critical to appropriately administer and facilitate optimal use. Clouse's study compared health care use and associated costs in patients with migraine and patients without migraine in a managed-care organization. Clouse's study [25] indicates patients with migraine had greater morbidity in general, and incurred $64 \%$ greater costs in health care resource use as compared with patients without migraine. Thus, migraine medication prescription and use may mitigate total health care costs, and have favorable implications for the third party payers. This finding may underscore the significance of our findings, as increased pharmacy cost resulting from antimigraine medications may by justified by total medical care cost reduction in patients with migraine (after adjusting for covariates).

Patients report headache as one of the most commonly reported reasons for ED visits [26, 27]. These visits may represent an annual cost ranging from $\$ 600$ million to nearly $\$ 2$ billion [12]. Our study also revealed that the percentage of patients with at least one migraine-related or all-cause ED visit was 7.4 or $12.3 \%$ lower in the patients using antimigraine medications than those not using antimigraine medications. Thus, lower medical utilization and costs could be expected in patients subsequent to medication initiation. In addition, using agents for migraine prophylaxis might be considered to manage the disease and control medical costs. Migraine prophylaxis is aimed at preventing frequent attacks, including migraine severity and length that often incurs high costs for pain relief, diagnostic services, and medical care. Wertz et al. [28] reported that headache-related resource utilization and costs were significantly lowered after initiation of preventive migraine treatment in a sample of a large managedcare population. Therefore, appropriate preventive therapy may reduce the disease burden and medical utilization.

Our study also suggests suboptimal migraine therapy, which is consistent with previous report. Among patients with migraine diagnosis, only $57 \%$ took antimigraine medications. Notably, although pharmacy cost was reduced without taking prescription drugs, total health care costs were increased due to heavy costs on medical utilization. Table 3 showed that those not using antimigraine drugs presented higher frequency of ED visits and total number of outpatient visits related to migraine. These results suggested that poor health outcomes and disease management 
Table 2 Characteristics of the study population $(n=465)$

\begin{tabular}{|c|c|c|c|c|}
\hline Variable & $\begin{array}{l}\text { All patients } \\
(n=465)\end{array}$ & $\begin{array}{l}\text { Antimigraine } \\
\text { drug users }(n=365)\end{array}$ & $\begin{array}{l}\text { No antimigraine } \\
\text { drug users }(n=100)\end{array}$ & $p$ value \\
\hline Age (years), mean (SD) & $43.5(10.9)$ & $43.8(10.9)$ & $42.3(11.0)$ & 0.210 \\
\hline Gender female, $n(\%)$ & $433(93.1)$ & $338(92.6)$ & $95(95.0)$ & 0.402 \\
\hline CGI, mean (SD) & $2.4(2.3)$ & $2.4(2.3)$ & $2.7(2.2)$ & 0.150 \\
\hline RI, mean (SD) & $17.6(10.5)$ & $17.7(10.3)$ & $17.5(11.3)$ & 0.861 \\
\hline Depression, $n(\%)$ & $307(66.0)$ & $240(65.8)$ & $67(67.0)$ & 0.816 \\
\hline Diagnosis of migraine, $n(\%)$ & $233(50.1)$ & $133(36.4)$ & $100(100)^{\mathrm{a}}$ & $<0.001$ \\
\hline
\end{tabular}

$C G I$ care gap index, $R I$ risk index, $S D$ standard deviation

${ }^{a}$ Patients who neither used antimigraine drugs nor had migraine diagnosis were not included in the study

Table 3 Medical utilization and health care costs of the study population by antimigraine medication use $(n=465)$
$E D$ emergency department, $S D$ standard deviation

\begin{tabular}{|c|c|c|c|}
\hline Variable & $\begin{array}{l}\text { Antimigraine drug } \\
\text { users }(n=365)\end{array}$ & $\begin{array}{l}\text { No antimigraine } \\
\text { drug users }(n=100)\end{array}$ & $p$ value \\
\hline \multicolumn{4}{|l|}{ All-cause medical utilization } \\
\hline Hospitalization, $n(\%)$ & $39(10.7)$ & $15(15.0)$ & 0.233 \\
\hline ED visits, $n(\%)$ & $83(22.7)$ & $35(35.0)$ & 0.013 \\
\hline Total number of outpatient visits, mean (SD) & $13.2(11.9)$ & $15.3(15.6)$ & 0.220 \\
\hline \multicolumn{4}{|l|}{ Migraine-related medical utilization } \\
\hline Hospitalization, $n(\%)$ & 0 & $3(3.0)$ & $<0.001$ \\
\hline ED visits, $n(\%)$ & $14(3.8)$ & $11(11.0)$ & 0.005 \\
\hline Total number of outpatient visits, mean (SD) & $0.8(1.8)$ & $1.4(1.2)$ & $<0.001$ \\
\hline \multicolumn{4}{|l|}{ All-cause health care costs $(\$)$, mean (median) } \\
\hline Medical & 7,043.7 (1921.4) & $10,450.6(3352.0)$ & 0.019 \\
\hline Pharmacy & $2,827.5(1408.1)$ & $1,817.3(753.1)$ & $<0.001$ \\
\hline Total & $9,871.2(4648.1)$ & $12,267.9(5267.3)$ & 0.633 \\
\hline \multicolumn{4}{|l|}{ Migraine-related costs (\$), mean (median) } \\
\hline Medical & $149.3(0)$ & $634.1(100.3)$ & $<0.001$ \\
\hline Pharmacy & $516.1(201.9)$ & 0 & $<0.001$ \\
\hline Total & $665.4(283.5)$ & $634.1(100.3)$ & 0.001 \\
\hline
\end{tabular}

Table 4 Associations between health care costs and the use of antimigraine medications

\begin{tabular}{|c|c|c|c|}
\hline \multirow[t]{2}{*}{ Independent variables } & \multicolumn{3}{|l|}{ Estimated coefficient (SE) } \\
\hline & $\begin{array}{l}\text { Dependent variable: } \log \\
\text { (total all-cause health care costs) }\end{array}$ & $\begin{array}{l}\text { Dependent variable: } \log \\
\text { (all-cause medical costs) }\end{array}$ & $\begin{array}{l}\text { Dependent variable: } \log \\
\text { (total migraine-related costs) }\end{array}$ \\
\hline Antimigraine medication use (yes vs. no) & $-0.30(0.12)^{* *}$ & $-0.55(0.17)^{* * *}$ & $0.62(0.18)^{* * *}$ \\
\hline Diagnosis of migraine (yes vs. no) & $-0.30(0.10)^{* *}$ & $-0.37(0.14)^{* *}$ & $1.17(0.15)^{* * *}$ \\
\hline Age (years) & $-0.01(0.28)^{*}$ & $-0.02(0.01)^{* *}$ & $0.02(0.01)^{* *}$ \\
\hline Gender (female vs. male) & $0.21(0.18)$ & $0.17(0.23)$ & $-0.15(0.25)$ \\
\hline CGI & $0.05(0.02)^{*}$ & $0.05(0.03)$ & $0.05(0.03)$ \\
\hline RI & $0.08(0.01)^{* * *}$ & $0.08(0.01)^{* * *}$ & $0.01(0.01)$ \\
\hline Comorbid depression (yes vs. no) & $0.15(0.10)$ & $0.19(0.13)$ & $0.04(0.14)$ \\
\hline
\end{tabular}

$C G I$ care gap index, $R I$ risk index, $S E$ standard error

$* p<0.05, * * p<0.01, * * * p<0.001$

might be associated with inadequate antimigraine medication use. Based on this evidence, there is a need to improve the quality of migraine care, and particularly provide physicians and patients with therapeutic options that are effective and well tolerated. Moreover, we also found that two-thirds of all patients in the study has 
depression diagnosis or used antidepressant medications. Studies showed that depression and migraine are highly correlated and might be bidirectional. That is, migraine may cause psychiatric conditions, vice versa or both $[23,29]$. Both of the diseases significantly decrease healthrelated quality of life [8]. Thus, assessing depressive disorders in migraine patients may augment migraine care quality.

These findings, derived from employer-sponsored claims data, suggested antimigraine medication use may be associated with reduced total medical utilization and health care costs. The study results indicate opportunities to understand self-reported care and needs of employees with headache. We may further investigate migraineurs' quality of lives and productivity via survey tools. Informed by the results of this study, we may develop intervention strategies to mitigate both direct (health care plan costs) and indirect (loss productivity and absenteeism) cost. More importantly, our results indicate a manner to improve migraine care, thereby increasing employees' the quality of care via treatment optimization and targeted implementation.

Although this study provides evidence regarding the associations among antimigraine medication use, diagnosis of migraine, and resource utilization, we concede some study limitations. First, the retrospective cross-sectional study design restricts the ability to establish causal inferences related to antimigraine medication use. Second, some of these patients could use over-the-counter (OTC) medications instead of prescription drugs to manage the headache, subsequently biasing our claims-based analyses. Additionally, some patients receiving antimigraine medications without migraine diagnosis code could occur in the administrative data. Third, we used a diagnosis of depression or antidepressant medication use as a comorbid depression. It is possible that some of these patients received antidepressant agents for the treatment of conditions other than depression. Finally, the claims data provide information on prescribing patterns only rather than on actual medication use. Therefore, we suggest further investigations include patient self-reported medication use using a survey tool.

\section{Conclusions}

Noted limitations notwithstanding, the study results suggest inadequate pharmacotherapy in migraine treatment. After controlling for covariates, antimigraine prescription drug use was associated with lower total medical utilization and health care costs. This suggests appropriately managing a specific chronicity, potentially inflating diseasespecific expenditures, can favorably impact total health care costs. Further studies should investigate patient self-reported care and needs to manage headache and develop effective intervention to improve patient quality of life and productivity.

Acknowledgments The Authors acknowledge the support of Francesca Holzheimer, the dedicated advisor at The Advisory Board Company (Washington D.C., US), for data analysis.

Conflict of interest The authors declared that they have no conflict of interest.

Open Access This article is distributed under the terms of the Creative Commons Attribution License which permits any use, distribution and reproduction in any medium, provided the original author(s) and source are credited.

\section{References}

1. Lipton RB, Scher AI, Kolodner K, Liberman J, Steiner TJ, Stewart WF (2002) Migraine in the United States: Epidemiology and patterns of health care use. Neurology 58:885-894

2. Lipton RB, Stewart WF, Diamond S, Diamonds ML, Reed M (2001) Prevalence and burden of migraine in the United States: Data from the american migraine study II. Headache 41:646-657

3. Diamond S, Bigal ME, Silberstein S, Loder E, Reed M, Lipton RB (2007) Patterns of diagnosis and acute and preventive treatment for migraine in the United States: Results from the American migraine prevalence and prevention study. Headache 47:355363

4. Stang PE, Osterhaus JT (1993) Impact of migraine in the United States: Data from the national health interview survey. Headache 33:29-35

5. Lipton RB, Stewart WF, von Korff M (1997) Burden of migraine: Societal costs and therapeutic opportunities. Neurology 48:S4-S9

6. Landy SH, Runken MC, Bell CF, Higbie RL, Haskins LS (2011) Assessing the impact of migraine onset on work productivity. J Occup Environ Med 53:74-81

7. Manack AN, Buse DC, Lipton RB (2011) Chronic migraine: Epidemiology and disease burden. Curr Pain Headache Rep 15:70-78

8. Lipton RB, Hamelsky SW, Kolodner KB, Steiner TJ, Stewart WF (2000) Migraine, quality of life, and depression: A populationbased case-control study. Neurology 55:629-635

9. Smith TR, Nicholson RA, Banks JW (2010) Migraine education improves quality of life in a primary care setting. Headache 50:600-612

10. Mennini FS, Gitto L, Martelletti P (2008) Improving care through health economics analyses: Cost of illness and headache. J Headache Pain 9:199-206

11. Hu XH, Markson LE, Lipton RB, Stewart WF, Berger ML (1999) Burden of migraine in the United States: Disability and economic costs. Arch Intern Med 159:813-818

12. Goldberg LD (2005) The cost of migraine and its treatment. Am J Manag Care 11:S62-S67

13. Bigal ME, Serrano D, Reed M, Lipton RB (2008) Chronic migraine in the population: Burden, diagnosis, and satisfaction with treatment. Neurology 71:559-566

14. Sokol MC, McGuigan KA, Verbrugge RR, Epstein RS (2005) Impact of medication adherence on hospitalization risk and healthcare cost. Med Care 43:521-530

15. Wu J, Seiber E, Lacombe VA, Nahata MC, Balkrishnan R (2011) Medical utilization and costs associated with statin adherence in 
medicaid enrollees with type 2 diabetes. Ann Pharmacother 45:342-349

16. Aubert RE, Yao J, Xia F, Garavaglia SB (2010) Is there a relationship between early statin compliance and a reduction in healthcare utilization? Am J Manag Care 16:459-466

17. Simpson RJ, Signorovitch J, Birnbaum H, Ivanova J, Connolly C, Kidolezi Y, Kuznik A (2009) Cardiovascular and economic outcomes after initiation of lipid-lowering therapy with atorvastatin vs simvastatin in an employed population. Mayo Clin Proc 84:1065-1072

18. Balkrishnan R, Rajagopalan R, Camacho FT, Huston SA, Murray FT, Anderson RT (2003) Predictors of medication adherence and associated health care costs in an older population with type 2 diabetes mellitus: A longitudinal cohort study. Clin Ther 25:2958-2971

19. Fishman P, Black L (1999) Indirect costs of migraine in a managed care population. Cephalalgia 19:50-57 (discussion 1)

20. Lofland JH, Frick KD (2006) Workplace absenteeism and aspects of access to health care for individuals with migraine headache. Headache 46:563-576

21. Stewart WF, Wood GC, Razzaghi H, Reed ML, Lipton RB (2008) Work impact of migraine headaches. J Occup Environ Med 50:736-745
22. Louter MA, Veen G, Ferrari MD, Zitman FG, Terwindt GM (2010) Migraine and depression should be treated concurrently. Ned Tijdschr Geneeskd 154:A1044

23. Frediani F, Villani V (2007) Migraine and depression. Neurol Sci 28(Suppl 2):S161-S165

24. Gautam S, Singh S (2008) Predicting overall and impactable future cost with the D2Hawkeye risk modeling system. http: Ilwww. d2hawkeyeservices.com. Accessed 12 November 2010

25. Clouse JC, Osterhaus JT (1994) Healthcare resource use and costs associated with migraine in a managed healthcare setting. Ann Pharmacother 28:659-664

26. McCaig LF, Burt CW (2004) National hospital ambulatory medical care survey: 2002 emergency department summary. Adv Data 340:1-34

27. McCaig LF, Nawar EW (2006) National hospital ambulatory medical care survey: 2004 emergency department summary. Adv Data 372:1-29

28. Wertz DA, Quimbo RM, Yaldo AZ, Rupnow MF (2009) Resource utilization impact of topiramate for migraine prevention in the managed-care setting. Curr Med Res Opin 25:499-503

29. Sheftell FD, Atlas SJ (2002) Migraine and psychiatric comorbidity: From theory and hypotheses to clinical application. Headache 42:934-944 